\title{
Mass Transport Effects on Electroreduction of Carbon Dioxide
}

\author{
Tiek Aun Tan ${ }^{1}$, Sara Yasina binti Yusuf ${ }^{1}$ and Umi Fazara Muhd Ali ${ }^{1}$ \\ ${ }^{1}$ Universiti Malaysia Perlis
}

\begin{abstract}
The electrochemical reduction of carbon dioxide $\left(\mathrm{CO}_{2}\right)$ into formic acid $(\mathrm{HCOOH})$ on a Sn cathode is governed by mass transport. This work investigates the effects of mass transport of $\mathrm{CO}_{2}$ to a Sn plated electrode on $\mathrm{CO}_{2}$ reduction. First, a potential of $-1.9 \mathrm{~V} v \mathrm{SCE}$ is applied to the cathode for two hours at different rotating cathode speeds. It is found that at a rotating speed of $240 \mathrm{rpm}$, the obtained current density is $70.91 \mathrm{Am}$ ${ }^{2}$ which increases to $108.67 \mathrm{Am}^{-2}$ at $540 \mathrm{rpm}$ and to $123.47 \mathrm{Am}^{-2}$ at $960 \mathrm{rpm}$. The samples are analyzed using HPLC and is found to contain $\mathrm{HCOOH}$. $\mathrm{HCOOH}$ decreases when the rotating speed of cathode is increased. To account for $\mathrm{H}_{2}$ evolution, cyclic voltammetry is carried out. The catholyte undergoes pre-electrolysis with a Pt cathode and purged with $N_{2}$. The Pt cathode is then replaced with a Sn plated carbon cathode and cyclic voltammetry with a maximum negative potential of $-2.5 \mathrm{~V} v \mathrm{SCE}$ is carried out on the system to account for $\mathrm{H}_{2}$ evolution. Then the catholyte is saturated with $\mathrm{CO}_{2}$ and cyclic voltammetry is repeated on the system. $\mathrm{CO}_{2}$ reduction is accounted by subtracting the effects of $\mathrm{H}_{2}$ evolution from the $\mathrm{CO}_{2}$ cyclic voltammgram. This is done at varying rotating cathode speed at $240 \mathrm{rpm}, 540 \mathrm{rpm}$, and $960 \mathrm{rpm}$. When the Sn cathode is rotated at $240 \mathrm{rpm}$, $\mathrm{CO}_{2}$ reduction initaties at circa $-0.7 \mathrm{~V}$ vs SHE and the difference in area under the $\mathrm{N}_{2}$ and $\mathrm{CO}_{2}$ curve is calculated to be $7.926 \times 10^{-4} \mathrm{AV}$. When the cathode rotating speed is increased to $540 \mathrm{rpm}$, the difference in area under the $\mathrm{N}_{2}$ and $\mathrm{CO}_{2}$ curve is calculated to be $4.85 \times 10^{-4} \mathrm{AV}$. When the cathode rotating speed is further increased to $960 \mathrm{rpm}$, a slight drop is suffered with the difference in area under the $\mathrm{N}_{2}$ and $\mathrm{CO}_{2}$ curve calculated to be $4.54 \times 10^{-4} \mathrm{AV}$. It can be concluded that increasing the mass transport of $\mathrm{CO}_{2}$ does not necessarily improve reduction performance possibly due to migration of $\mathrm{HCOOH}$ to the anode where it is oxidized back into $\mathrm{CO}_{2}$ and $\mathrm{OH}^{-}$to the cathode to form $\mathrm{H}_{2} \mathrm{O}$, further reduction of $\mathrm{HCOOH}$ into other products, the formation of a Sn- $\mathrm{CO}_{2}$ complex, and competing reduction of impurities at the cathode.
\end{abstract}

Keywords: Carbon dioxide, Electroreduction, Electrolyte, Formic acid

\section{Introduction}

Electrochemical reduction can valorise $\mathrm{CO}_{2}$ into $\mathrm{HCOOH}$ on a $\mathrm{Sn}$ cathode (Eq. 1).

$\mathrm{CO}_{2}+\mathrm{H}^{+}+2 e^{-} \rightarrow \mathrm{HCOO}^{-} \quad E_{0}=-0.225 \mathrm{~V}$ vs SHE

$\mathrm{HCOO}^{-}$requires relatively little energy to form and can be converted with high Faradaic efficiencies [1]. The process first requires $\mathrm{CO}_{2(\mathrm{~g})}$ or $\mathrm{CO}_{2(\mathrm{aq})}$ to be adsorbed onto the $\mathrm{Sn}$ electrode. Electricity is used to supply electrons for the reduction process of the $\mathrm{CO}_{2(a d)}$ to $\mathrm{CO}_{2(a d)}{ }^{-}$. The radical anion then desorps into the electrolyte and undergoes protonation to form $\mathrm{HCOO}$. The $\mathrm{HCOO}^{\circ}$ radical then receives another electron to form $\mathrm{HCOO}^{-}$and a $\mathrm{H}^{+}$to form $\mathrm{HCOOH}$ [2]. This is shown in Eq. 2 to Eq. 7.

$$
\begin{aligned}
& \mathrm{CO}_{2(g)} \rightarrow \mathrm{CO}_{2(a q)} \\
& \mathrm{CO}_{2(a q)} \rightarrow \mathrm{CO}_{2(a d)} \\
& \mathrm{CO}_{2(a d)}+e^{-} \rightarrow \mathrm{CO}_{2(a d)}{ }^{-} \\
& \mathrm{CO}_{2(a d)}{ }^{-} \rightarrow \mathrm{CO}_{2}^{--} \\
& \mathrm{CO}_{2}^{--}+\mathrm{H}^{+} \rightarrow \mathrm{HCOO}^{-} \\
& \mathrm{HCOO}^{-}+e^{-} \rightarrow \mathrm{HCOO}^{-} \\
& \mathrm{HCOO}^{-}+\mathrm{H}^{+} \rightarrow \mathrm{HCOOH}^{-}
\end{aligned}
$$


The major competing reaction is $H_{2}$ evolution from the reduction of $H^{+}$present in the solvent. The $H_{2}$ evolution can be written as in Eq. 9 to Eq. 11. [3]

$H^{+}+e^{-} \rightarrow H_{a d s}$

$H_{a d s}+H_{a d s} \rightarrow H_{2}$

$H^{+}+e^{-}+H_{a d s} \rightarrow H_{2}$

Hori claims that $\mathrm{H}_{\text {ads }}$ deactivates the $\mathrm{CO}_{2}{ }^{--}$radical to $\mathrm{CO}_{a d s}$ [3].

$\mathrm{CO}_{2}{ }^{--}+\mathrm{H}_{\text {ads }} \rightarrow \mathrm{CO}_{\text {ads }}+\mathrm{OH}^{-}$

Chen et.al. reported that $H_{a d s}$ reduces the electro-active surface area of the cathode and increase its electrical resistance [4].

This paper presents the findings on the effects of the transport of $\mathrm{CO}_{2}$ to the cathode.

\section{Methodology}

A $\mathrm{Sn}$ plated glassy carbon rotating disc is the cathode, and $\mathrm{Pt}$ wire is the anode. The electrolyte is $\mathrm{H}_{2} \mathrm{O}$ with $\mathrm{KHCO}_{3}$ as supporting electrolyte. The reactor is batch type with separation of the catholyte and anolyte achieved using a Nafion membrane. The selective permeable membrane separating the anode and cathode chambers stops the oxidation of the newly reduced $\mathrm{HCOO}^{-}$back into $\mathrm{CO}_{2}$ and the reduction of $\mathrm{O}_{2}$ into $\mathrm{OH}^{-}$ as shown in Eq. 12 and Eq. 13.

$\mathrm{HCOO}^{-} \rightarrow \mathrm{CO}_{2}+\mathrm{H}^{+}+2 e^{-}$

$\mathrm{O}_{2}+\mathrm{H}_{2} \mathrm{O}+4 e^{-} \rightarrow 4 \mathrm{OH}^{-}$

Chrono amperometry, high pressure liquid chromatography and cyclic voltammetry is used to investigate the mass transport effects of $\mathrm{CO}_{2}$ on $\mathrm{CO}_{2}$ reduction.

\subsection{Chrono Amperometry}

Chrono Amperometry is carried out on the system to investigate the current performance of the electrolysis as a function of time at a set potential. Three sets of experiment are carried out where the electrode is rotated at a speed of 240, 540, and $960 \mathrm{rpm}$ respectively. Prior to each set of experiment, the remaining $S n$ will be stripped off first and then re-deposited under the same conditions to ensure the thickness of the $S n$ layer for each set run is similar. A fresh batch of electrolyte is also prepared and purified through pre-electrolysis.

A potential of $-1.9 \mathrm{~V}$ vs SCE is applied on the cathode for two hours and the current performance is recorded. The potentials were later converted to $\mathrm{V}$ vs SHE to account for $\mathrm{pH}$ change.

\subsection{High Pressure Liquid Chromatography}

High Pressure Liquid Chromatography is used to confirm the presence of $\mathrm{HCOOH}$. The column is a RP C-18 column provided by Merck and the mobile phase $0.01 \mathrm{M} \mathrm{KH}_{2} \mathrm{PO}_{4}+5 \%$ methanol acidified to $\mathrm{pH} 2.7$ with $\mathrm{H}_{3} \mathrm{PO}_{4}$. The samples were flowed at $1 \mathrm{ml} / \mathrm{min}$. $\mathrm{HCOOH}$ is detected at $220 \mathrm{~nm} \mathrm{UV}$ wavelength. The results are compared with a standard curve of a known sample containing $10 \% \mathrm{HCOOH}$.

\subsection{Cyclic Voltammetry}

Cyclic voltammetry is carried out on the system to investigate the current performance of the electrolysis as a function of potential. Three sets of experiment are carried out where the electrode is rotated at a speed of 240, 540, and $960 \mathrm{rpm}$ respectively. Prior to each set of experiment, the remaining $S n$ will be stripped off first and then re-deposited under the same conditions to ensure the thickness of the $S n$ layer for each set run is similar. A fresh batch of electrolyte is also prepared and purified through pre-electrolysis.

A competing reaction, $\mathrm{H}_{2}$ evolution is unavoidable as it initiates at potentials close to $\mathrm{CO}_{2}$ reduction. In each set of experiment, to account for current due to $\mathrm{H}_{2}$ evolution, first the electrolyte is purged with $\mathrm{N}_{2}$ to remove 
$\mathrm{CO}_{2}$, then a $\mathrm{CV}$ is ran on the sample and the resulting current which initiates at circa $-0.7 \mathrm{~V}$ vs SHE must be due to $\mathrm{H}_{2}$ evolving at the cathode. The set up at this point cannot be disturbed as even a slight change in position of any of the electrodes will alter the Ohmic resistance between them. Then $\mathrm{CO}_{2}$ is reintroduced into the sample and a $\mathrm{CV}$ is carried out on the sample. This time, the current initiated at circa $-1.5 \mathrm{~V}$ vs SCE is due to $\mathrm{CO}_{2}$ reduction and $\mathrm{H}_{2}$ evolution. The effect of $\mathrm{H}_{2}$ evolution is then subtracted out using data from the first $\mathrm{CV}$ run.

\section{Results}

\subsection{Chrono Amperogram}

A potential of $-1.9 \mathrm{~V}$ vs SCE is applied on the electrolyte for two hours with varying rotating speeds of 240 rpm, $540 \mathrm{rpm}$, and $960 \mathrm{rpm}$.

For reduction of $\mathrm{CO}_{2}$ at $240 \mathrm{rpm}$, the theoretical current density is $0.20 \mathrm{Am}^{-2}$ while the obtained current density is $70.91 \mathrm{Am}-2$. For reduction of $\mathrm{CO}_{2}$ at $540 \mathrm{rpm}$, the theoretical current density is $0.30 \mathrm{Am}^{-2}$ while the obtained current density is $108.67 \mathrm{Am}^{-2}$. For reduction of $\mathrm{CO}_{2}$ at $960 \mathrm{rpm}$, the theoretical current density is 0.40 $\mathrm{Am}^{-2}$ while the obtained current density is $123.47 \mathrm{Am}^{-2}$. There are huge discrepancies between the theoretical current density and the obtained current density. The theoretical current density only considers the mass transport limited current for a two electron reduction of the electro-active $\mathrm{CO}_{2}$ species and does not factor in other current density sources that may be present in the process. In reality, there may be other reactions consuming electrons such as $\mathrm{H}_{2}$ evolution or reduction of the cation originating from the salt used to improve the conductivity of ultra pure $\mathrm{H}_{2} \mathrm{O}$.

Fig 1 shows the reduction of $\mathrm{CO}_{2}$ on a $\mathrm{Sn}$ cathode rotating at $240 \mathrm{rpm}, 540 \mathrm{rpm}$, and $960 \mathrm{rpm}$ respectively for two hours. When the rotating speed is $240 \mathrm{rpm}$, the charge passed is $10.01 \mathrm{Q}$. The Nernst Diffusion Layer is calculated to be $3.21 \times 10^{-5} \mathrm{~m}$. When the rotating speed is increased to $540 \mathrm{rpm}$, a higher charge is passed being 15.34 Q. Improved mass transport of feedstock to the cathode allows reduction to proceed at a higher rate. The Nernst Diffusion Layer is calculated to be $2.14 \times 10^{-5} \mathrm{~m}$. When the rotating speed is $960 \mathrm{rpm}$, an even higher charge is passed being 17.42 Q. Improved mass transport of feedstock to the cathode allows reduction to proceed at a higher rate. This does not necessarily mean that $\mathrm{CO}_{2}$ is being reduced at a higher rate. Referring to Fig 3, background reaction, i.e. $\mathrm{H}_{2}$ evolution may also proceed at a higher rate. The Nernst Diffusion Layer is calculated to be $1.60 \times 10^{-5} \mathrm{~m}$.

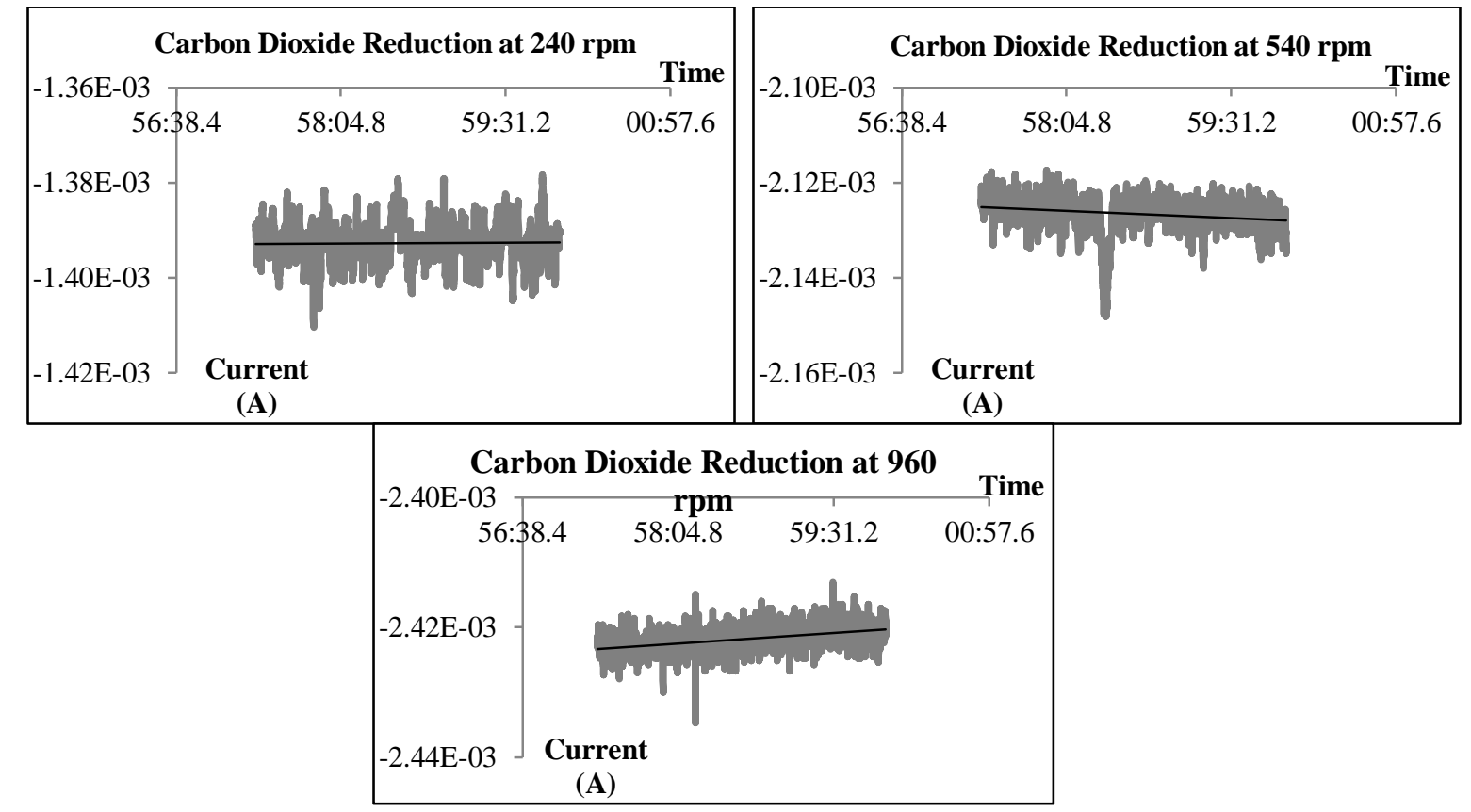

Fig. 1: $\mathrm{CO}_{2}$ Reduction at $240 \mathrm{rpm}, 540 \mathrm{rpm}$, and $960 \mathrm{rpm}$ respectively for 2 hours. 
If the theoretical current density is used to calculate the theoretical amount of $\mathrm{HCOOH}$ that is obtained, then the theoretical amount of charge going into the system is then $0.028 \mathrm{Q}$ for $\mathrm{CO}_{2}$ reduction at $240 \mathrm{rpm}, 0.042 \mathrm{Q}$ for $\mathrm{CO}_{2}$ reduction at $540 \mathrm{rpm}$ and $0.056 \mathrm{Q}$ at for $\mathrm{CO}_{2}$ reduction at $960 \mathrm{rpm}$. The theoretical amount of $\mathrm{HCOOH}$ that can be produced is $6.68 \times 10^{-6} \mathrm{~g}$ for $\mathrm{CO}_{2}$ reduction at $240 \mathrm{rpm}$ which increases to $1.00 \times 10^{-5} \mathrm{~g}$ for $\mathrm{CO}_{2}$ reduction at $540 \mathrm{rpm}$ and to $1.34 \times 10^{-5} \mathrm{~g}$ for $\mathrm{CO}_{2}$ reduction at $960 \mathrm{rpm}$. The Nernst Potential for $\mathrm{CO}_{2}$ reduction at $240 \mathrm{rpm}$ is then $-0.289 \mathrm{~V}$ vs SHE which increases to $-0.294 \mathrm{~V}$ vs SHE for $\mathrm{CO}_{2}$ reduction at $540 \mathrm{rpm}$ and to $-0.298 \mathrm{~V}$ vs $\mathrm{SHE}$ for $\mathrm{CO}_{2}$ reduction at $960 \mathrm{rpm}$. The Nernst Potential for $\mathrm{CO}_{2}$ reduction at $240 \mathrm{rpm}$ is then $-0.533 \mathrm{~V}$ vs SCE which increases to $-0.538 \mathrm{~V}$ vs SCE for $\mathrm{CO}_{2}$ reduction at $540 \mathrm{rpm}$ and to $-0.542 \mathrm{~V}$ vs SCE for $\mathrm{CO}_{2}$ reduction at $960 \mathrm{rpm}$.

If the obtained current density is used to calculate the amount of $\mathrm{HCOOH}$ that is obtained, then the amount of charge going into the system is then $10.01 \mathrm{Q}$ for $\mathrm{CO}_{2}$ reduction at $240 \mathrm{rpm}, 15.34 \mathrm{Q}$ for $\mathrm{CO}_{2}$ reduction at 540 rpm and $17.42 \mathrm{Q}$ at for $\mathrm{CO}_{2}$ reduction at $960 \mathrm{rpm}$. The theoretical amount of $\mathrm{HCOOH}$ that can be produced is $2.39 \times 10^{-3} \mathrm{~g}$ for $\mathrm{CO}_{2}$ reduction at $240 \mathrm{rpm}$ which increases to $3.66 \times 10^{-3}$ for $\mathrm{CO}_{2}$ reduction at $540 \mathrm{rpm}$ and to $4.15 \times 10^{-3}$ for $\mathrm{CO}_{2}$ reduction at $960 \mathrm{rpm}$. The Nernst Potential for $\mathrm{CO}_{2}$ reduction at $240 \mathrm{rpm}$ is then $-0.366 \mathrm{~V}$ vs SHE which increases to $-0.371 \mathrm{~V}$ vs SHE for $\mathrm{CO}_{2}$ reduction at $540 \mathrm{rpm}$ and to $-0.373 \mathrm{~V}$ vs $\mathrm{SHE}$ for $\mathrm{CO}_{2}$ reduction at $960 \mathrm{rpm}$. The Nernst Potential for $\mathrm{CO}_{2}$ reduction at $240 \mathrm{rpm}$ is then $-0.610 \mathrm{~V}$ vs SCE which increases to $-0.615 \mathrm{~V}$ vs SCE for $\mathrm{CO}_{2}$ reduction at $540 \mathrm{rpm}$ and to $-0.617 \mathrm{~V}$ vs SCE for $\mathrm{CO}_{2}$ reduction at 960 rpm.

This assumes that all charge provided to the system is used to reduce $\mathrm{CO}_{2}$ into $\mathrm{HCOOH}$ at $100 \%$ efficiency.

\subsection{High Pressure Liquid Cromatograph}

A maximum shift of $0.18 \mathrm{~min}$ between the standard $\mathrm{HCOOH}$ curves and the sample $\mathrm{HCOOH}$ curves are observed. However the presence of $\mathrm{HCOOH}$ is still confirmed but not quantified due to a difficulty in measuring concentrations of less than $1 \%$. The area under the $\mathrm{HCOOH}$ curve is a representation of the quantity of $\mathrm{HCOOH}$ produced and is used as a relative measure. It is found that with an increase of rotation speed which provides better mass transport, the area under the $\mathrm{HCOOH}$ curve decreases, which meant that less $\mathrm{HCOOH}$ is produced. The decrease in area is documented as 301,612 for $240 \mathrm{rpm}$, to 270,934 for $540 \mathrm{rpm}$ and 231,568 for $960 \mathrm{rpm}$. Fig 2 shows the $\mathrm{HCOOH}$ peak for $\mathrm{CO}_{2}$ on a $\mathrm{Sn}$ cathode rotating at $240 \mathrm{rpm}, 540 \mathrm{rpm}$ and $960 \mathrm{rpm}$ for two hours.
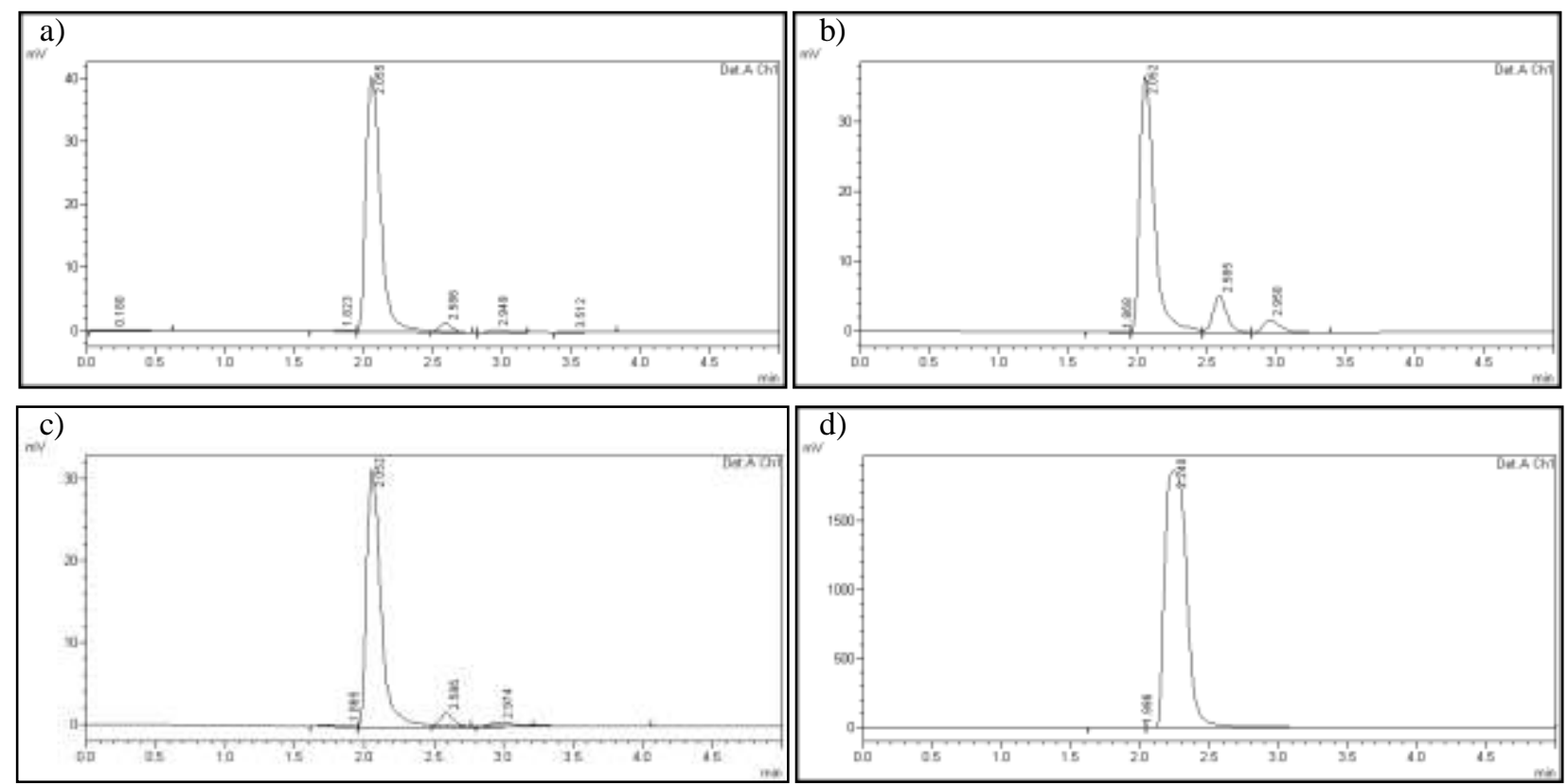

Fig. 2: a) $\mathrm{HCOOH}$ peak for $\mathrm{CO}_{2}$ Reduction at $240 \mathrm{rpm}$, b) $\mathrm{HCOOH}$ peak for $\mathrm{CO}_{2}$ Reduction at $540 \mathrm{rpm}$, c) $\mathrm{HCOOH}$ peak for $\mathrm{CO}_{2}$ Reduction at $960 \mathrm{rpm}$, d) $10 \% \mathrm{HCOOH}$ peak 


\subsection{Cyclic Voltammgrams}

If the forward pass potential sweep is asymmetric as the backward pass, it is likely due to the evolution of $\mathrm{H}_{2}$ on the electrode surface of the electrode. The $\mathrm{H}_{2}$ disrupts the current flowing through the system by absorping on the electrode surface. The degree of asymmetry for the forward and backward pass in the $\mathrm{CO}_{2}$ reduction sweep is less pronounced than in the $\mathrm{H}_{2}$ evolution sweep. This suggests that $\mathrm{CO}_{2}$ is preferentially reduced over $\mathrm{H}_{2}$. Hence it might be erroneous to directly subtract the effect of $\mathrm{H}_{2}$ evolution from the reduction of $\mathrm{CO}_{2}$ and $\mathrm{H}_{2}$ because it only represents the worst case scenario, which is $\mathrm{H}_{2}$ evolution occurring at the maximum without being impeded by the reduction of $\mathrm{CO}_{2}$ [3]. Only data from the forward pass, the potential sweep from $-0.5 \mathrm{~V}$ vs SHE to $-1.72 \mathrm{~V}$ vs SHE is used. These values are still meaningful relative to each other because the degree of impedance caused by $\mathrm{H}_{2}$ evolution is assumed similar for all runs.

The reduction curve at circa $-0.1 \mathrm{~V}$ vs $\mathrm{SHE}$ is due to part of the $\mathrm{Sn}$ reducing into $\mathrm{SnO} \mathrm{O}_{x}$ [5]. This is beneficial to the process as $\mathrm{SnO}_{x}$ play a bigger role than $\mathrm{Sn}$ in the reduction of $\mathrm{CO}_{2}$. This reduction process is the same for all runs as its cyclic voltammetric profile is similar for all same type of curve. In the reduction of $\mathrm{CO}_{2}, \mathrm{SnO}_{x}$ formation always initiates at a less negative potential than for the $\mathrm{H}_{2}$ evolution run. In the backward pass, there exist a positive current circa $-0.1 \mathrm{~V}$ vs SHE. The current is the stripping region where $\operatorname{SnO}_{x}$ is oxidised to $S n$ and $S n$ into $S n^{2+}$ [5].

The effects of mass transport were studied by varying the rotating speed of the cathode which in turn governs the transport of $\mathrm{CO}_{2}$ to the cathode. The initiating potential for $\mathrm{CO}_{2}$ reduction does not vary significantly for all rotating speeds.

Fig 3 shows the graph of reduction of $\mathrm{CO}_{2}$ on a Sn cathode rotating at $240 \mathrm{rpm}, 540 \mathrm{rpm}$, and $960 \mathrm{rpm}$ respectively. $\mathrm{CO}_{2}$ reduction and $\mathrm{H}_{2}$ evolution initiates at nearly the same potential, circa $-1.5 \mathrm{~V}$ vs $\mathrm{SCE}$. When the cathode is rotated at $240 \mathrm{rpm}$, the difference in area under the $\mathrm{N}_{2}$ and $\mathrm{CO}_{2}$ curve is calculated to be $7.926 \times$ $10^{-5} \mathrm{AV}$. When the cathode rotating speed is increased to $540 \mathrm{rpm}$, the difference in area under the $\mathrm{N}_{2}$ and $\mathrm{CO}_{2}$ curve is calculated to be $4.85 \times 10^{-4} \mathrm{AV}$. When the cathode rotating speed is further increased to $960 \mathrm{rpm}$, a slight drop is suffered the difference in area under the $\mathrm{N}_{2}$ and $\mathrm{CO}_{2}$ curve is calculated to be $4.54 \times 10^{-4} \mathrm{AV}$.

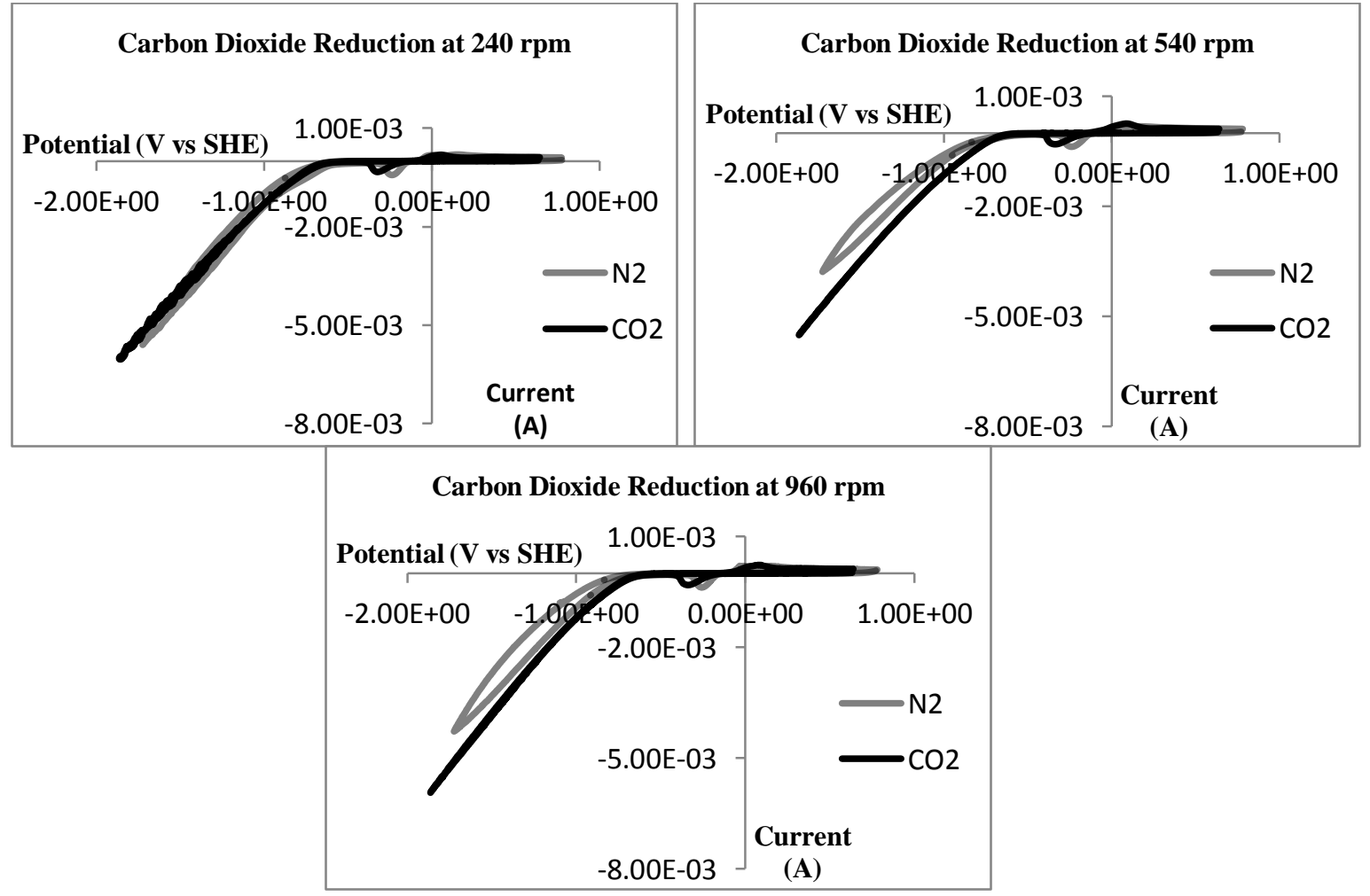

Fig. 3: Cyclic Voltammgram for $\mathrm{CO}_{2}$ Reduction at $240 \mathrm{rpm}, 540 \mathrm{rpm}$ and $960 \mathrm{rpm}$ respectively 


\subsection{Discussion}

Chrono amperogram data shows that with increasing rotating speed, a higher current is passed, meaning that a reduction reaction proceeds more vigorously. High pressure liquid chromatography data shows that the $\mathrm{HCOOH}$ decreases with increasing rotating speed. Cyclic voltammetry data shows that the difference in area under the $\mathrm{N}_{2}$ and $\mathrm{CO}_{2}$ curve increases drastically from a rotating speed of $240 \mathrm{rpm}$ to $540 \mathrm{rpm}$, and only drop slightly with an increase to $960 \mathrm{rpm}$. These may mean a few things; migration of $\mathrm{HCOOH}$ to the anode where it is oxidized back into $\mathrm{CO}_{2}$ and $\mathrm{OH}^{-}$to the cathode to form $\mathrm{H}_{2} \mathrm{O}$, further reduction of $\mathrm{HCOOH}$ into other products, the formation of a $\mathrm{Sn}-\mathrm{CO}_{2}$ complex, when the bond between $\mathrm{Sn}$ and $\mathrm{CO}_{2}$ does not always break and the $\mathrm{CO}_{2}$ carries the $\mathrm{Sn}$ into the bulk electrolyte as $\mathrm{Sn}-\mathrm{CO}_{2}$, and competing reduction of impurities at the cathode [6]. This effect may be more prominent at high rotating speeds where $\mathrm{CO}_{2}$ transport to the cathode is improved.

\section{Conclusions}

When the rotating speed of the $\mathrm{Sn}$ cathode is increased, $\mathrm{CO}_{2}$ mass transport to the cathode increases. This results in a higher current density. The recorded current density for reduction of $\mathrm{CO}_{2}$ at $240 \mathrm{rpm}, 540 \mathrm{rpm}$, and $960 \mathrm{rpm}$ are $70.91 \mathrm{Am}^{-2}, 108.67 \mathrm{Am}^{-2}$, and 123.47 $\mathrm{Am}^{-2}$ respectively. This is however much higher than the calculated theoretical current density which expects $0.20 \mathrm{Am}^{-2}, 0.30 \mathrm{Am}^{-2}$, and $0.40 \mathrm{Am}^{-2}$ respectively. The theoretical current density only considers the mass transport limited current for a two electron reduction of the electro-active $\mathrm{CO}_{2}$ species and does not factor in other current density sources that may be present in the process. In reality, there may be other reactions consuming electrons meant for the $\mathrm{CO}_{2}$ reduction. It does not necessarily mean that $\mathrm{CO}_{2}$ is being reduced at a higher rate. A major competing reaction is $\mathrm{H}_{2}$ evolution. Cyclic voltammetry is used to study the effects of $\mathrm{H}_{2}$ evolution. The area under the graph for reduction of $\mathrm{CO}_{2}$ which can be directly related to the current density, at $240 \mathrm{rpm}, 540 \mathrm{rpm}$, and $960 \mathrm{rpm}$ are $7.926 \times 10^{-5} \mathrm{AV}, 4.85 \times 10^{-4}$ $\mathrm{AV}$, and $4.54 \times 10^{-4} \mathrm{AV}$ respectively. Other competing reactions may be caused by migration of $\mathrm{HCOOH}$ to the anode where it is oxidized back into $\mathrm{CO}_{2}$ and $\mathrm{OH}^{-}$to the cathode to form $\mathrm{H}_{2} \mathrm{O}$, further reduction of $\mathrm{HCOOH}$ into other products, the formation of a $\mathrm{Sn}-\mathrm{CO}_{2}$ complex, when the bond between $\mathrm{Sn}$ and $\mathrm{CO}_{2}$ does not always break and the $\mathrm{CO}_{2}$ carries the $\mathrm{Sn}$ into the bulk electrolyte as $\mathrm{Sn}-\mathrm{CO}_{2}$, and competing reduction of impurities at the cathode.

\section{Acknowledgement}

This work is supported by the Research Acculturation Grant Scheme 9018-00033.

\section{References}

[1] A. S. Agarwal. (September 2011). The electrochemical reduction of carbon dioxide to formate/formic acid: engineering and economic feasibility. Chem. Pub. Soc. [Online]. 4(12). pp. 1301-1310. Available: http://onlinelibrary.wiley.com/doi/10.1002/cssc.201100220/abstract.

[2] W. Li. "Electrocatalytic reduction of $\mathrm{CO} 2$ to small organic molecule fuels on metal catalysts," in ACS Symposium Series 2010, pp. 56-76.

[3] Y. Hori. (2008). Electrochemical CO2 reduction on metal electrodes. Modern Aspects of Electrochemistry. Springer. pp. 89-188.

http://dx.doi.org/10.1007/978-0-387-49489-0_3

[4] F. Chen. (April 2012). Study on hydrogen evolution reaction at a graphite electrode in the all-Vanadium Redox Flow Battery. Int. J. Electrochem. Sci. [Online]. pp. 3750-3764. Available: http://www.electrochemsci.org/papers/vol7/7043750.pdf

[5] W. Lv. (December 2013). Studies on the faradaic efficiency for electrochemical reduction of carbon dioxide to formate on tin electrode. Journal of Power Sources. pp. 276-281.

[6] H. Li. (April 2005). The electro-reduction of carbon dioxide in a continuous reactor. Journal of Applied Electrochemistry. pp. 955-965.

http://dx.doi.org/10.1007/s10800-005-7173-4 